\title{
Factors associated with abstinence after a recent smoking cessation attempt across 28 European Union member states
}

\author{
Chung-Mei M. Cheung ${ }^{1}$, Constantine I. Vardavas ${ }^{2}$, Filippos T. Filippidis ${ }^{1}$
}

\begin{abstract}
INTRODUCTION There is a lack of information regarding factors associated with successful smoking cessation on a population and European Union (EU)-wide level. Our study seeks to explore individual and country-level factors associated with abstinence after a recent smoking cessation attempt across the EU.

METHOdS We obtained data from the March 2017 Special Eurobarometer 87.1 $(\mathrm{n}=27901)$. Regression analysis was performed on a subset of 1472 individuals who made quit attempts in the past 12 months. Sociodemographic, policy and country-level factors were assessed using logistic regression among smokers and ex-smokers who attempted to quit approximately 12 months before the survey date. We defined and examined the Cessation Ratio (ratio of number of recent quitters to those who did not succeed) across $28 \mathrm{EU}$ Member States.

RESULTS In all, $14.9 \%(n=1018)$ of current smokers and $8.80 \%(n=454)$ of exsmokers attempted to quit in approximately the last 12 months $(n=1472)$. Cessation Ratios ranged from 0.182 (95\% CI: 0.045-0.319) in Estonia to 1.060 (95\% CI: 0.262-1.860) in Sweden. There is a quadratic, U-shaped relationship between odds of quitting and smoking prevalence. The lowest odds of cessation were observed at a prevalence of $26.3 \%$, with higher odds of cessation observed above and below this point. Respondents who reported financial difficulties were less likely to quit (AOR $=0.66 ; 95 \%$ CI: $0.52-0.83$ ). There was no association of likelihood of success with other sociodemographic factors or the Tobacco Control Scale treatment score.

CONCLUSIONS These findings highlight a need for exploring reasons behind the variation in likelihood of abstinence following a recent quit attempt, in order to design policies targeted at population groups or countries that need greater support.
\end{abstract}

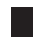

\section{AFFILIATION}

1 Public Health Policy Evaluation Unit, School of Public Health, Imperial College London, London, United Kingdom

2 School of Medicine, University of Crete, Heraklion, Greece

\section{CORRESPONDENCE TO}

Chung-Mei M. Cheung. School of Public Health, Imperial College London, 310 The Reynolds Building, St Dunstan's Road, London W6 8rp, United Kingdom. E-mail: maggie.

cheung@doctors.org.uk

\section{KEYWORDS}

European Union, socioeconomic status, smoking cessation, successful cessation

Received: 18 November 2020 Revised: 31 December 2020

Accepted: 3 January 2020

\section{INTRODUCTION}

Tobacco smoking is the largest preventable health risk in the European Union (EU), contributing to 0.7 million deaths annually ${ }^{1}$. Smokers die on average 10 years younger than non-smokers from vascular, neoplastic and respiratory diseases, but this risk is halved if abstinence is achieved before the age of 50 years, and is almost completely avoidable with cessation before the age of 30 years ${ }^{2}$.

It is estimated that in an average year, around one-third of current smokers will make an attempt to quit ${ }^{3}$. Amongst those who make an attempt, only a minority are still abstinent a year later, with studies reporting abstinence rates at one year of $6-20 \%{ }^{3-5}$. Research indicates that most relapses occur in the first six months following a quit attempt and these are associated with biological, social and psychological factors ${ }^{6}$.

Recent literature suggests that there are two elements in smoking cessation: the decision to make 
an attempt and maintaining abstinence. Studies have found that those of higher socioeconomic status, with lower levels of nicotine dependence and greater selfmotivation to quit are more likely to make a cessation attempt ${ }^{7,8}$. With regard to successful cessation, while some studies have found associations between individual factors including gender, age and education attainment with successful cessation ${ }^{9-11}$, others have found mixed and inconsistent evidence between sociodemographic factors and successful cessation ${ }^{12}$. However, there seems to be more consistency in evidence suggesting that higher socioeconomic status (SES) is associated with increased likelihood of cessation ${ }^{9,13}$. Additionally, studies looking into sociodemographic factors associated with quit attempts are typically countryspecific and most have been performed in individual countries, which may not translate directly to an EU-wide context ${ }^{14,15}$. Therefore, much uncertainty remains around sociodemographic as well as country-level predictors of a successful quit attempt.

Furthermore, there is mixed evidence surrounding the role of e-cigarettes in smoking cessation. A cross-sectional study across 28 European Member States showed that amongst current and ex-smokers who ever tried to quit smoking, $10.6 \%$ attempted using e-cigarettes, and amongst those who tried to quit in the past 12 months, $43.6 \%$ tried to do so with e-cigarettes, suggesting rising popularity of e-cigarettes as a cessation method ${ }^{16}$. While some studies, such as one amongst English former and current smokers performed by Brown et al. ${ }^{17}$, suggest a higher abstinence rate when using e-cigarettes as a cessation method, others, including a systematic review by Kalkhoran and Glantz ${ }^{18}$, have found no or a negative association between e-cigarette use and successful cessation ${ }^{16,18,19}$. Further clarification of the role of e-cigarettes in cessation could have important public health implications due to their rising popularity and general belief that they are less harmful than tobacco smoking ${ }^{20,21}$.

In addition, there is much variability in the definition of successful cessation, from abstinence at 6 weeks, 3 months, to one year ${ }^{14,15,22,23}$. Considering the variability of interventions and the different types of smoking cessation aids used in cessation research, it is difficult to standardize and compare results across studies. Studies estimating population- level smoking cessation also often employ the 'quit ratio', which measures the number of former smokers as a proportion of ever smokers (current plus former smokers) $)^{9}$. While this allows results to be comparable across cohorts and between countries, again it offers limited information on the temporality of smoking cessation, which could be helpful in assessing the impact of tobacco control policies, for example.

To supplement the current evidence, we conducted an analysis of the 2017 wave of the Eurobarometer survey in order to evaluate current progress in smoking cessation and explore potential predictors of recent successful smoking cessation across 28 EU Member States. This allows us to compare data and examine factors associated with successful cessation across 28 different countries and on a European level, and to potentially explore how national and EU-wide policies might be associated with smoking cessation as well as identify countries or population groups that may need additional support.

\section{METHODS}

\section{Data source}

The main data were obtained from the Special Eurobarometer 87.1 (March 2017) conducted by the European Commission across 28 EU Member States (MS) between 18 and 27 March $2017^{24}$. A multistage probability sampling strategy was used to identify representative samples of the population aged $\geq 15$ years. Primary sampling units (PSUs) proportional to population size were selected from regions of each country, and households were selected systematically through a standard random route. The household member whose birthday was closest to the date of the interview was selected. Face-to-face interviews were conducted in participants' own homes in an appropriate national language. Resultant self-reported data were weighted for age, sex and area of residence for analysis. The total sample size was $n=27901$. The full methodology and questionnaire are published in the Eurobarometer summary report ${ }^{1}$. No ethical approval was required as the data sets are publicly available, and no identifiable data were used. The data underlying the results presented in the study are available from the Eurostat data base, available from https://ec.europa.eu/eurostat/web/main and 
also the European Commission Eurobarometer 87.1 2017:ZA6861 doi:10.4232/1.1292 available from https://dbk.gesis.org/dbksearch/sdesc2. asp?no $=6861 \& \mathrm{db}=\mathrm{e} \& \mathrm{doi}=10.4232 / 1.12915$.

\section{Measures}

\section{Smoking status}

Participants' smoking status was assessed with the question: 'Regarding smoking cigarettes, cigars, cigarillos or a pipe, which of the following applies to you?'. Those who answered 'currently smoke' were classified as 'current smokers' and those who answered 'used to smoke but have stopped' were classified as 'former smokers'.

\section{E-cigarette use}

Use of electronic cigarettes was assessed with the question: 'Which of the following statements about the use of electronic cigarettes or any similar electronic devices (e-shisha, e-pipe) applies to you?'. Those who responded 'currently use electronic cigarettes or similar electronic devices (e.g. e-shisha, e-pipe)' were classified as 'current e-cigarette users'.

\section{Smoking cessation attempts}

We identified a subset of current and former smokers who made a recent quit attempt, approximately within the last 12 months before the date of the survey. Past attempts to quit in current smokers were assessed using the questions: 'Have you ever tried to quit smoking?' with the answers providing a time frame ('Yes, in the last 12 months', 'Yes, more than a year ago' and 'No, never'). Those who answered 'Yes, in the last 12 months' were included in our analysis as 'unsuccessful quitters'.

Former smokers were not asked the same question in the survey. We therefore combined two variables, current age and the age at which the respondent reported to have stopped smoking. Those who quit at an age 0 to 1 year younger than their current age were considered to have quit smoking approximately within the last 12 months, although it has to be noted that, based on this definition, this group could potentially include respondents who quit smoking up to 24 months before the survey. We classified them in our analysis as 'recent quitters' and we refer to their last quit attempt as 'successful', although this does not necessary imply long-term cessation.
To estimate likelihood of abstinence following a recent cessation attempt on a population-level, we introduced and estimated the new concept of 'Cessation Ratio', which we defined as the ratio of the number of recent quitters to unsuccessful quitters, as described above, for each of the $28 \mathrm{EU}$ MS (Cessation Ratio = recent quitters/unsuccessful quitters). Based on this definition the Cessation Ratio could take any value $\geq 0$. For example, a value of zero means that none of the smokers who recently attempted to quit was abstinent at the time of the survey; a value of one means that half of those who recently attempted to quit (recent quitters + unsuccessful quitters) were abstinent at the time of the survey; values higher than one imply that a majority of those who recently attempted to quit remained abstinent at the time of the survey. This is different to the commonly used 'quit ratio' which estimates the proportion of former smokers amongst ever smokers (current and former smokers).

\section{Socioeconomic data}

The survey also collected self-reported demographic data including age (15-24; 25-39; 40-54; $\geq 55$ years), gender (male; female), age leaving formal education $(\leq 15 ; 16-19 ; \geq 20$ years), area of residence (rural; small town; large town), and European region of residence (Northern; Eastern; Southern; and Western Europe). Socioeconomic status was assessed with self-reported social class (higher class; upper middle class; middle class; lower middle class; working class) and a proxy measure for financial difficulty using the question: 'During the last twelve months, would you say you had difficulties paying your bills at the end of the month?'. Those who answered 'almost never/never' were classified as not having financial difficulties and those who answered 'from time to time/most of the time' were classified as having some financial difficulties.

\section{Country-level data}

Prevalence of cigarette and e-cigarette use was estimated for each EU Member State using the relevant questions in the Eurobarometer survey. Data on the comprehensiveness and implementation of tobacco control policies were obtained from the 2016 Tobacco Control Scale (TCS) ${ }^{25}$. Each country is awarded up to 100 points for tobacco taxation 
(30), public and workplace smoking bans (22), public information campaigns (15), comprehensive advertising bans (13), effective health warnings on tobacco products (10), and smoking cessation treatment provisions (10). In this analysis, we have used the score for cessation treatment only (range: 4-9 points). The Gross Domestic Product (GDP) per capita and unemployment rates for each country in 2016 were obtained from the Eurostat database ${ }^{26}$.

\section{Statistical analysis}

Descriptive results are presented as weighted percentage with 95\% confidence interval (CI). Regression results are presented as adjusted odds ratio (AOR) with 95\% CI. The regression analysis was performed in a subgroup of the main data set, which included only respondents who attempted to quit smoking approximately in the last 12 months $[\mathrm{n}=1472$, sum of recent $(n=454)$ and unsuccessful quitters $(n=1018)$ as defined above]. Weights provided by the Eurobarometer were applied to the subset analysis of this study and included in any statistical models employed; more details on weights are provided in the Eurobarometer summary report ${ }^{24}$. We used the Akaike Information Criterion to determine the optimal specification of the regression model. We explored whether a multilevel logistic regression model with EU Member States as a higher level of analysis would be more appropriate than a simple logistic regression model by conducting a Likelihood Ratio test, but it did not improve the fit of the model and hence we opted for simple logistic regression.

Our logistic regression model assessed the association between the odds of a successful quit attempt and age, sex, financial difficulties, the country's TCS treatment score, and prevalence of tobacco smoking. We also assessed other sociodemographic factors including age of leaving formal education, area of residence, European region of residence and self-reported social class, as well as the other country-level factors described above. None of these improved the overall fit of the model or significantly associated with the outcome and therefore were excluded from the final analysis. After comparing multiple models with the inclusion of different variables using Akaike Information Criterion, including both linear and quadratic variations of smoking prevalence, we found that the quadratic form of the association between smoking prevalence and the odds of successful quit attempt was the one that fitted best with the data. As a result, our final logistic regression model assessing the odds of a successful quit attempt included age, sex, financial difficulties, TCS treatment score and prevalence of tobacco smoking (both linear and quadratic terms) as variables. We also conducted a sensitivity analysis with the full TCS score instead of the cessation-specific TCS score. In addition, we plotted unadjusted Cessation Ratios against smoking prevalence and present this in the Supplementary file.

All analyses were performed with Stata (version SE 15.1); the map was also created with Stata. Weights provided in the official Eurobarometer data set were used in all descriptive analyses to account for the sampling methodology. Observations with missing values were excluded from the analysis.

\section{RESULTS}

A total of 27901 participants were surveyed in March 2017, across 28 European Union Member States. Sociodemographic characteristics of survey respondents are summarized in Supplementary Table S1. Country-specific characteristics including GDP per capita, unemployment rate and TCS treatment scores are listed in Supplementary Table S2.

The prevalence of smoking across the EU was $26.1 \%$ (95\% CI: 25.3-27.0) with large differences between countries, ranging from $7.2 \%$ in Sweden to $36.6 \%$ in Greece (Table 1). Similarly, there were large variations in prevalence of current e-cigarette use, ranging from $0.18 \%$ in Italy to $5.04 \%$ in the United Kingdom. Among current smokers, 14.9\% $(n=1018)$ had tried to quit in the last 12 months (unsuccessful quitters), while among former smokers, $8.8 \%(n=454)$ reported having quit up to approximately one year before the time of the survey (recent quitters). A total of 1472 respondents were therefore included in our analysis as having attempted to quit smoking in approximately the last 12 months; 61 observations (4\%) were excluded due to missing values.

In our study subset, those with financial difficulties were less likely to have been successful in quitting than those without ( $\mathrm{AOR}=0.66$; 95\% CI: 0.52-0.83; $\mathrm{p}=0.001$ ) (Table 2). Gender, age, and 
Table 1. Smoking and e-cigarette prevalence, and cessation ratios across 28 European Union Member States, Eurobarometer 2017 ( $\mathrm{N}=27901)$

\begin{tabular}{|c|c|c|c|c|c|}
\hline Country & Sample size & $\begin{array}{l}\text { Smoking prevalence } \\
\quad \%(95 \% \text { CI })\end{array}$ & $\begin{array}{l}\text { Prevalence of } \\
\text { e-cigarette use } \\
\%(95 \% \text { CI })\end{array}$ & $\begin{array}{c}\text { Sample size included } \\
\text { in cessation ratio } \\
\text { analysis }\end{array}$ & $\begin{array}{l}\text { Cessation ratio } \\
\quad(95 \% \text { CI })\end{array}$ \\
\hline Austria & 1001 & $28.3(25.2-31.6)$ & $2.70(1.74-4.15)$ & 28 & $0.645(0.468-0.851)$ \\
\hline Belgium & 1023 & $19.2(16.6-22.0)$ & $3.52(2.44-5.06)$ & 70 & $0.826(0.410-1.240)$ \\
\hline Bulgaria & 1044 & $36.0(33.1-39.1)$ & $0.21(0.05-0.84)$ & 23 & $0.214(0-0.449)$ \\
\hline Croatia & 1048 & $35.2(32.2-38.3)$ & $0.36(0.13-0.97)$ & 47 & $0.509(0.186-0.833)$ \\
\hline Cyprus & 501 & $27.5(23.4-32.1)$ & $2.72(1.46-5.01)$ & 35 & $0.578(0.157-1.00)$ \\
\hline Czech Republic & 1058 & $28.9(26.1-31.9)$ & $1.27(0.71-2.24)$ & 37 & $0.509(0.143-0.875)$ \\
\hline Denmark & 1000 & $18.6(16.1-21.4)$ & $2.15(1.36-3.38)$ & 68 & $0.653(0.290-1.020)$ \\
\hline Estonia & 1017 & $23.3(20.4-26.5)$ & $1.50(0.71-2.24)$ & 62 & $0.182(0.045-0.319)$ \\
\hline Finland & 1012 & $20.1(17.5-23.0)$ & $1.27(0.67-2.41)$ & 73 & $0.453(0.214-0.692)$ \\
\hline France & 1004 & 35.9 (32.6-39.4) & $4.43(3.22-6.07)$ & 82 & $0.424(0.209-0.639)$ \\
\hline Germany & 1537 & $25.4(22.9-28.1)$ & $1.80(1.12-2.88)$ & 81 & $0.349(0.129-0.570)$ \\
\hline Greece & 1010 & $36.6(33.5-39.8)$ & $2.66(1.74-4.05)$ & 60 & $0.417(0.172-0.662)$ \\
\hline Hungary & 1053 & $26.6(23.8-29.6)$ & $0.58(0.23-1.47)$ & 32 & $0.588(0.130-1.050)$ \\
\hline Ireland & 1021 & 19.4 (16.9-22.2) & $2.01(1.27-3.15)$ & 69 & $0.365(0.162-0.568)$ \\
\hline Italy & 1022 & $24.6(22.0-27.5)$ & $0.18(0.04-0.71)$ & 10 & $0.380(0-0.912)$ \\
\hline Latvia & 1004 & $32.2(28.4-36.3)$ & $0.89(0.36-2.20)$ & 105 & $0.481(0.216-0.747)$ \\
\hline Lithuania & 1001 & $29.1(25.9-32.4)$ & $0.76(0.28-2.10)$ & 58 & $0.516(0.206-0.826)$ \\
\hline Luxembourg & 510 & $21.0(17.3-25.2)$ & $1.61(0.71-3.64)$ & 31 & $0.347(0.055-0.640)$ \\
\hline Malta & 500 & $24.0(19.7-28.9)$ & $1.95(0.89-4.20)$ & 29 & $0.249(0.015-0.482)$ \\
\hline Netherlands & 1015 & 19.5 (16.9-22.2) & $1.67(1.04-2.68)$ & 87 & $0.428(0.217-0.639)$ \\
\hline Poland & 1008 & $29.7(26.7-32.8)$ & $1.10(0.55-2.18)$ & 54 & $0.433(0.163-0.702)$ \\
\hline Portugal & 1061 & $25.6(23.0-28.4)$ & $0.94(0.48-1.80)$ & 25 & $0.632(0.120-1.140)$ \\
\hline Romania & 1033 & $28.0(25.2-30.9)$ & $0.46(0.18-1.15)$ & 32 & $0.292(0.041-0.543)$ \\
\hline Slovakia & 1014 & $26.3(23.4-29.5)$ & $0.26(0.08-0.85)$ & 40 & $0.301(0.101-0.621)$ \\
\hline Slovenia & 1027 & $27.9(25.0-31.0)$ & $0.62(0.22-1.71)$ & 36 & $0.399(0.091-0.708)$ \\
\hline Spain & 1024 & $27.5(24.7-30.4)$ & $0.52(0.21-1.25)$ & 59 & $0.434(0.186-0.682)$ \\
\hline Sweden & 1007 & $7.2(5.3-9.7)$ & $0.30(0.08-1.04)$ & 48 & $1.060(0.262-1.860)$ \\
\hline United Kingdom & 1346 & $17.4(15.1-20.0)$ & $5.04(3.75-6.75)$ & 91 & $0.594(0.271-0.917)$ \\
\hline
\end{tabular}

a Cessation Ratio is defined as the ratio of the number of 'recent quitters' to 'unsuccessful quitters', both defined in the Methods section.

TCS treatment score of the respondent's country of residence had no significant association with successful smoking cessation. We found a significant quadratic, U-shaped relationship between the odds of having been successful in a recent quit attempt and smoking prevalence of the EU MS (Figure 1). After adjusting for age, sex and TCS treatment score, our model estimated that an individual had the lowest odds of having been successful in quitting when living in a country where smoking prevalence was $26.3 \%$, with odds of success higher at each end of the prevalence spectrum. The sensitivity analysis conducted using the full TCS score instead of the cessation-specific TCS score yielded no significant difference to the main analysis.

There was wide variation amongst EU MS in their Cessation Ratios, ranging from 0.182 (95\% CI: 0.045-0.319) in Estonia to 1.060 (95\% CI: 0.2621.860 ) in Sweden (Table 1 and Supplementary Figure S1). Only Sweden and Belgium had a Cessation Ratio above 0.7, indicating high success in smoking cessation, with the majority of MS (21 out of 
Table 2. Associations of successful smoking cessation in past 12 months in $28 \mathrm{EU}$ MS, Eurobarometer 2017 $(\mathrm{N}=1472)$

\begin{tabular}{lll}
$\begin{array}{l}\text { Variables } \\
\text { OR (95\% CI) }\end{array}$ & $\begin{array}{c}\text { Successful quit } \\
\text { attempt } \\
\text { AOR (95\% CI) }\end{array}$ & $\begin{array}{c}\text { Successful quit } \\
\text { attempt }\end{array}$ \\
$\begin{array}{l}\text { Fenale (Ref.) } \\
\text { Male }\end{array}$ & 1.00 & 1.00 \\
Difficulties paying bills & $0.97(0.78-1.21)$ & $0.95(0.76-1.19)$ \\
Almost never/never (Ref.) & 1.00 & \\
$\begin{array}{l}\text { From time to time/most } \\
\text { of the time }\end{array}$ & $0.67(0.53-0.84)$ & $0.66(0.52-0.83)$ \\
Age (years) & & \\
$\geq 55$ (Ref.) & 1.00 & 1.00 \\
15-24 & $1.20(0.86-1.67)$ & $1.25(0.76-1.43)$ \\
25-39 & $1.13(0.85-1.52)$ & $1.25(0.93-1.69)$ \\
40-54 & $0.99(0.72-1.35)$ & $1.04(0.89-1.74)$ \\
Country-level smoking & & \\
$\begin{array}{l}\text { prevalence (per 10\% } \\
\text { change) }\end{array}$ & & \\
Linear term & & \\
Quadratic term & $0.66(0.15-0.82)$ & $0.34(0.14-0.79)$ \\
TCS score for treatment & $1.21(1.02-1.43)$ & $1.23(1.04-1.46)$ \\
\hline
\end{tabular}

OR: odds ratio. AOR: adjusted odds ratio. TCS: Tobacco Control Scale.

Figure 1. Correlation between odds of success in quit attempt and smoking prevalence, Eurobarometer 2017 with extrapolation

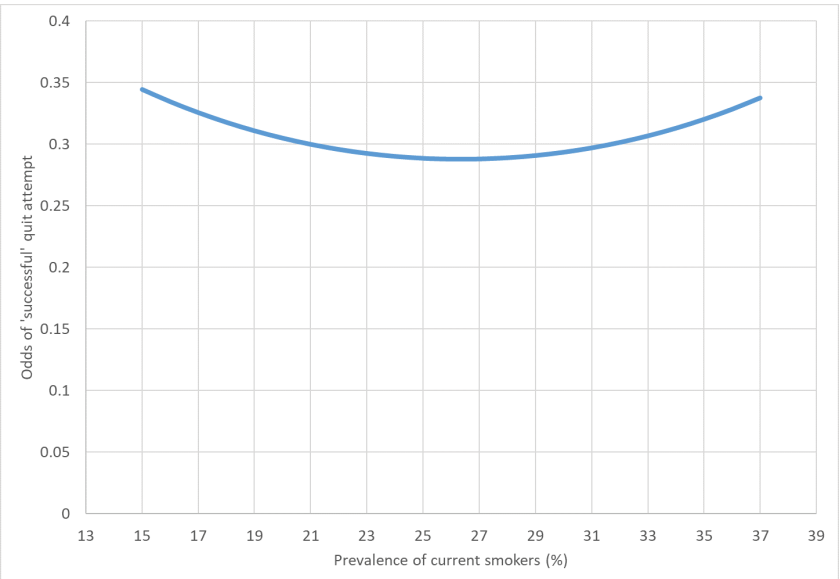

Created using Stata (version SE 15.1).

28 ) between 0.3 and 0.6 (Figure 2). The choropleth map of Figure 2 was created using Stata (version SE
Figure 2. Choropleth map showing cessation ratios across 28 European Union Member States

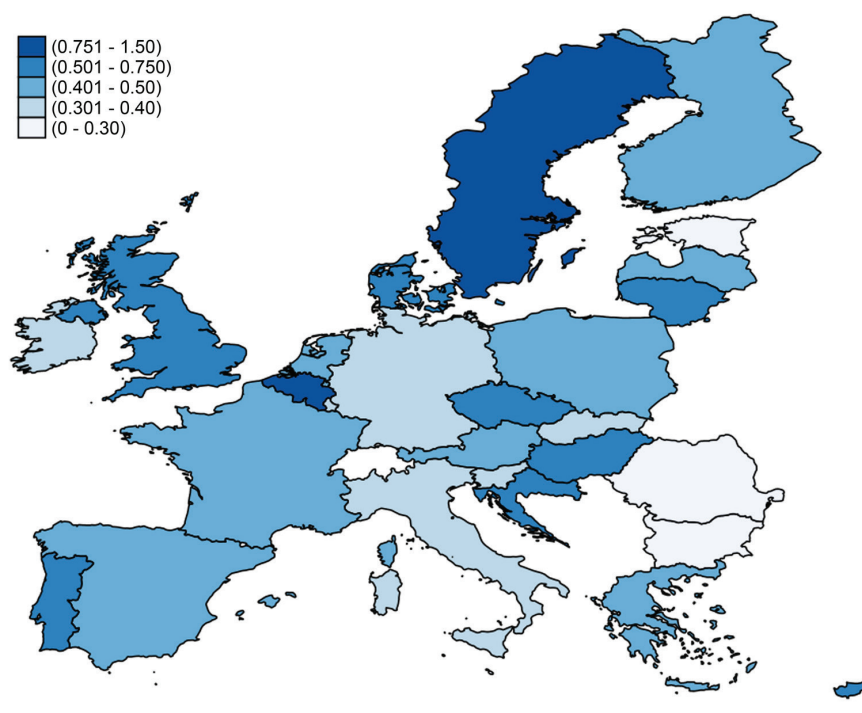

15.1) and republished from StataCorp under a CC BY license, with permission from StataCorp.

\section{DISCUSSION}

There is wide variation in the Cessation Ratios among the 28 EU MS sampled, with the highest Cessation Ratios found in Northern Europe. Amongst the study subset and on an individual level, having some financial difficulty, a proxy measure for SES status, was associated with a less successful quit attempt. We did not find significant associations between other sociodemographic factors including age and gender and the likelihood of a successful quit attempt. On a country level, we found a quadratic relationship between smoking prevalence and odds of a successful quit attempt. There were no significant associations between odds of success and a country's GDP per capita, unemployment rate, prevalence of e-cigarettes or TCS treatment score.

In our analysis, some Northern European countries had higher Cessation Ratios compared to Southern European countries, although during our modelling no significant association between odds of success and European region of residence was demonstrated. Previous literature has suggested that Southern Europeans are less likely to use smoking cessation aids when attempting to quit ${ }^{27}$, which has been associated with lower likelihood of success, but this association is inconsistent ${ }^{28,29}$. 
Southern European countries may also have less comprehensive community healthcare and primary care framework to support smoking cessation activities, which can affect motivation, efficacy and likelihood of success ${ }^{30}$.

We found a quadratic relationship between the odds of quitting and smoking prevalence among our study sample, with a transition point at a prevalence of around $26.3 \%$. The relationship was U-shaped indicating that the odds of quitting were optimal when smoking prevalence is either very low or very high. Although country-specific factors, such as socioeconomic and cultural differences between European countries as well as accuracy of self-reporting pose challenges in formulating an overarching explanation of this finding, it might reflect a true phenomenon. In communities where smoking prevalence is high, there may be a large number of smokers who are able to quit relatively easily when effective tobacco control measures such as smoking bans or tax increases are implemented. With lower - but still high - smoking prevalence, the proportion of 'easy quitters' might be lower, hence, smokers find it on average more difficult to quit. This could explain the upper end of the association and provide some support to the so-called 'Hardening Hypothesis' ${ }^{31}$, although there has been a growing body of evidence against this where 'hardening' has not been demonstrated ${ }^{32,33}$.

However, on the other end of the U-shape relationship, the odds of success are higher where prevalence is lower. It is possible that when prevalence of tobacco smoking becomes quite low, smoking becomes denormalized and less socially appropriate, which might motivate smokers to quit and make them more effective in their quit attempts. This is echoed in existing literature ${ }^{32,33}$. There is also literature suggesting 'softening' of the smoking population as opposed to 'hardening' - with lower overall smoking prevalence, there could be a higher prevalence of 'light smokers' and a lower prevalence of 'hardcore smokers', and as a result the overall population-level likelihood of successful cessation increase $^{34,35}$. Lower smoking prevalence also implies that there are more former smokers, who can provide support and serve as role models. This is supported by a study by Giovino et al. ${ }^{36}$ showing that selfefficacy for quitting, intention to quit and successful abstinence at 3 months are all higher where prevalence is lower. Self-efficacy itself is a predictor of successful cessation ${ }^{7,15}$, which could explain the trend we found.

We have also compared our findings, adjusted for individual factors of age, sex and TCS treatment score, against a plot between unadjusted Cessation Ratios against prevalence (Supplementary Table S3 and Figure S1). In the unadjusted plot, there appears to be an inverse association between Cessation Ratio and prevalence, but it is influenced by outliers (Sweden) and can be confounded by age and other sociodemographic factors which differ between EU member states, as they may be at different stages of the tobacco epidemic ${ }^{37}$. Once these individual factors had been adjusted, as in our analysis, the relationship becomes U-shaped and more complex, as demonstrated by our findings. Further research on this association may provide more clarity and disentangle the influence of individual and country-level factors.

We found a significant association between having financial difficulties, a proxy for socioeconomic status, and the odds of a successful quit attempt, which is in line with current evidence ${ }^{3,12,14,16,22,23}$. It possibly reflects the fact that having financial difficulties is likely a confluence of conditions that influence successful cessation, rather than an independent factor. Existing tobacco control policies have been found to be most effective in higher SES groups ${ }^{9}$, and having access to healthcare and therefore medical advice and cessation assistance through insurance, which are associated with higher likelihood of successful cessation $^{5}$. In addition, lower odds of success have been demonstrated in high levels of nicotine dependence $^{7,38}$, poorer mental health ${ }^{39,40}$ and living in a home that permitted smoking ${ }^{5}$, all of which are conditions that are more likely amongst smokers in lower SES groups ${ }^{41}$. These factors would be an important area for future research assessing associations with successful cessation, but have not been included in our study as they were beyond the scope of our data set.

Aside from socioeconomic status, we found no significant associations between other sociodemographic factors and odds of successful cessation. Earlier analyses have found similar 
results ${ }^{12,15,16}$. Although in one study males were found to be more likely to make a quit attempt ${ }^{10}$, they were not more likely to be successful.

Previous studies have shown that a higher TCS treatment score, or having policies to increase access to cessation aids, was associated with higher rates of smoking cessation ${ }^{42-44}$. In contrast, we did not find any association between TCS treatment score and having been successful in a recent quit attempt. However, our analysis was restricted to those who had made an attempt in the past 12 months. Treatment provisions could influence both a smoker's decision to make a quit attempt and their chances of success through complex mechanisms; our study was not able to disentangle such associations but further research in this area would be beneficial to clarify the mechanisms through which availability of cessation support affects cessation efforts and success. For instance, there has been a significant increase in the use of e-cigarettes by the public as a smoking cessation aid ${ }^{45}$, but their effectiveness is still unclear and therefore have not been included in most national treatment efforts $^{16-18,46}$. Our analysis echoes previous studies and did not find any significant positive associations between the prevalence of e-cigarettes and the likelihood of successful cessation ${ }^{16,18}$.

\section{Strengths and limitations}

The Eurobarometer survey is representative of the EU population aged $\geq 15$ years and the sampling methodology has been standardized across $28 \mathrm{EU}$ MS, allowing valid comparisons and generalization of results across EU populations. Although there can be discrepancies between the Eurobarometer and national surveys due to differences in phrasing, sampling methods and sample sizes, existing literature finds a positive and significant correlation between Eurobarometer and national survey data ${ }^{47}$. Our study also looks at attempts to quit within approximately the last 12 months, providing a more focused time frame and allows interpretation alongside any concurrent tobacco control policies. It improves upon the more commonly used quit ratio, which is a cumulative measure including all former smokers, regardless of when they achieved abstinence.

However, the selection of current and former smokers who were included in the analysis was based on different questions suggesting a slightly different time frame for recent successful or unsuccessful quit attempts. As a result, the Cessation Ratio we estimated should not be interpreted as an actual ratio of successful over unsuccessful quitters, which was impossible to estimate with the available data. Nevertheless, the standardized methodology of Eurobarometer across Member States allowed us to make country-level comparisons using this ratio as a proxy indicator of smoking cessation success. The sample of current and former smokers with recent quit attempts was small across the countries, which introduces uncertainty in some of the estimates. Additionally, although there is high agreement between self-reported cigarette use and biochemical testing ${ }^{48,49}$, self-reporting is less accurate for smoking cessation ${ }^{50,51}$, especially considering that Eurobarometer questions did not define a time frame for smoking abstinence.

\section{CONCLUSIONS}

Lower socioeconomic status was significantly associated with lower odds of a successful quit attempt, which could exacerbate existing health inequalities in the EU. We also found large variations in Cessation Ratios across the EU Member States. Future research could therefore explore any country-specific and individual factors that explain such differences, in order to inform policies that target specific populations. Finally, we reported a U-shape association between the odds of successful smoking cessation in the past year and smoking prevalence. Despite the limitations of our dataset, our finding suggests that there may be a critical threshold in smoking prevalence below which quitting becomes easier for remaining smokers who attempt to quit. This would be of great importance for nations which are aiming to reduce the burden of smoking.

\section{REFERENCES}

1. European Commission. Special Eurobarometer 458: Attitudes of Europeans towards tobacco and electronic cigarettes. Brussels: European Union Directorate; 2017. https://op.europa.eu/en/publication-detail/-/ publication/2f01a3d1-0af2-11e8-966a-01aa75ed71a1. Accessed December 31, 2020.

2. Doll R, Peto R, Boreham J, Sutherland I. Mortality in relation to smoking: 50 years' observations on 
male British doctors. BMJ. 2004;328(7455):1519. doi:10.1136/bmj.38142.554479.AE

3. Caleyachetty A, Lewis S, McNeill A, Leonardi-Bee J. Struggling to make ends meet: exploring pathways to understand why smokers in financial difficulties are less likely to quit successfully. Eur J Public Health. 2012;11(Suppl 1):41-48. doi:10.1093/eurpub/ckr199

4. Estabrooks PA, Gaglio B, Morse EF, Smith T, Edwards A, Glasgow RE. Defining and understanding success at smoking reduction: A mixed-methods study. Addict Behav. 2010;35(12):1113-1119. doi:10.1016/j.addbeh.2010.08.006

5. Yong LC, Luckhaupt SE, Li J, Calvert GM. Quit interest, quit attempt and recent cigarette smoking cessation in the US working population, 2010. Occup Environ Med. 2014;71(6):405-414. doi:10.1136/oemed-2013-101852

6. El-Khoury Lesueur F, Bolze C, Melchior M. Factors associated with successful vs. unsuccessful smoking cessation: Data from a nationally representative study. Addict Behav. 2018;80:110-115. doi:10.1016/j.addbeh.2018.01.016

7. Hyland A, Borland R, Li Q, et al. Individual-level predictors of cessation behaviours among participants in the International Tobacco Control (ITC) Four Country Survey. Tob Control. 2006;15(Suppl 3):iii83-iii94. doi:10.1136/tc.2005.013516

8. Hyland A, Li Q, Bauer JE, Giovino GA, Steger C, Cummings KM. Predictors of cessation in a cohort of current and former smokers followed over 13 years. Nicotine Tob Res. 2004;6(Suppl 3):S363-S369. doi:10.1080/14622200412331320761

9. Bosdriesz JR, Willemsen MC, Stronks K, Kunst AE. Socioeconomic inequalities in smoking cessation in 11 European countries from 1987 to 2012. J Epidemiol Community Health. 2015;69(9):886-892. doi:10.1136/jech-2014-205171

10. Zhou X, Nonnemaker J, Sherrill B, Gilsenan AW, Coste F, West R. Attempts to quit smoking and relapse: factors associated with success or failure from the ATTEMPT cohort study. Addict Behav. 2009;34(4):365-373. doi:10.1016/j.addbeh.2008.11.013

11. Nagelhout GE, de Korte-de Boer D, Kunst AE, et al. Trends in socioeconomic inequalities in smoking prevalence, consumption, initiation, and cessation between 2001 and 2008 in the Netherlands. Findings from a national population survey. BMC Public Health. 2012;12(1):303. doi:10.1186/1471-2458-12-303

12. Vangeli E, Stapleton J, Smit ES, Borland R, West R. Predictors of attempts to stop smoking and their success in adult general population samples: a systematic review. Addiction. 2011;106(12):2110-2121. doi:10.1111/j.1360-0443.2011.03565.x

13. Huisman M, Kunst AE, Mackenbach JP. Educational inequalities in smoking among men and women aged 16 years and older in 11 European countries. Tob Control. 2005;14(2):106-113. doi:10.1136/tc.2004.008573

14. Kale D, Gilbert HM, Sutton S. Are predictors of making a quit attempt the same as predictors of 3-month abstinence from smoking? Findings from a sample of smokers recruited for a study of computer-tailored smoking cessation advice in primary care. Addiction. 2015;110(10):1653-1664. doi:10.1111/add.12972

15. Smit ES, Hoving C, Schelleman-Offermans K, West R, de Vries H. Predictors of successful and unsuccessful quit attempts among smokers motivated to quit. Addict Behav. 2014;39(9):1318-1324. doi:10.1016/j.addbeh.2014.04.017

16. Filippidis F, Laverty A, Vardavas C. Experimentation with e-cigarettes as a smoking cessation aid: a cross-sectional study in 28 European Union member states. BMJ Open. 2016;6(10):e012084. doi:10.1136/bmjopen-2016-012084

17. Brown J, Beard E, Kotz D, Michie S, West R. Real-world effectiveness of e-cigarettes when used to aid smoking cessation: a cross-sectional population study. Addiction. 2014;109(9):1531-1540. doi:10.1111/add.12623

18. Kalkhoran S, Glantz SA. E-cigarettes and smoking cessation in real-world and clinical settings: a systematic review and meta-analysis. Lancet Respir Med. 2016;4(2):116-128. doi:10.1016/S2213-2600(15)00521-4

19. Kulik M, Lisha N, Glantz S. E-cigarettes associated with depressed smoking cessation: A cross-sectional study of 28 European Union countries. Am J Prev Med. 2018;54(4):603-609. doi:10.1016/j.amepre.2017.12.017

20. Farsalinos KE, Poulas K, Voudris V, Le Houezec J. Electronic cigarette use in the European Union: analysis of a representative sample of 27460 Europeans from 28 countries. Addiction. 2016;111(11):2032-2040. doi:10.1111/add.13506

21. Vardavas CI, Filippidis FT, Agaku IT. Determinants and prevalence of e-cigarette use throughout the European Union: a secondary analysis of 26566 youth and adults from 27 Countries. Tob Control. 2015;24(5):442-448. doi:10.1136/tobaccocontrol-2013-051394

22. Levy DT, Yuan Z, Luo Y, Abrams DB. The Relationship of E-Cigarette Use to Cigarette Quit Attempts and Cessation: Insights From a Large, Nationally Representative U.S. Survey. Nicotine Tob Res. 2018;20(8):931-939. doi:10.1093/ntr/ntx166

23. Coppo A, Baldissera S, Migliardi A, et al. Quit attempts and smoking cessation in Italian adults (25-64 years): factors associated with attempts and successes. Eur J Public Health. 2017;27(4):717-722. doi:10.1093/eurpub/ckw262

24. European Commission, European Parliament. Eurobarometer 87.1 (2017). GESIS Data Archive, Cologne. ZA6861 Data file Version 1.2.0. Brussels: TNS Opinion; 2017. doi:10.4232/1.12922

25. Joossens L, Raw M. The Tobacco Control Scale 2016 in Europe. Brussels: Association of European Cancer Leagues; 2017. https://www.cancer.be/sites/default/ files/tobacco_control_scale.pdf. Accessed December 31, 2020.

26. European Commission. Eurostat database. https:// 
ec.europa.eu/eurostat/web/main/data/database. Accessed November 27, 2018.

27. Filippidis FT, Gerovasili V, Vardavas CI, Agaku IT, Tountas Y. Determinants of use of smoking cessation aids in 27 European countries. Prev Med. 2014;65:99-102. doi:10.1016/j.ypmed.2014.05.004

28. Van den Brand F, Nagelhout G, Hummel K, Willemsen MC, McNeil Ann, van Schayck O. Does free or lower cost smoking cessation medication stimulate quitting? Findings from the International Tobacco Control (ITC) Netherlands and UK surveys. Tob Control. 2019;28(Suppl 1):s61-67. doi:10.1136/tobaccocontrol-2017-054023

29. Williams MB, Beebe LA, Neas BR. State-Level Correlates of Unassisted Quit Attempts and Success. J Okla State Med Assoc. 2015;108(11):455-462. PMID:26817062.

30. Vardavas C, Symvoulakis E, Lionis C. Dealing with tobacco use and dependence within primary care: time for action. Tob Induc Dis. 2013;11(February):1-2. doi:10.1186/1617-9625-11-6

31. Hughes J. The hardening hypothesis: Is the ability to quit decreasing due to increasing nicotine dependence? A review and commentary. Drug Alcohol Depend. 2011;117(23):111-117. doi:10.1016/j.drugalcdep.2011.02.009

32. Biener L, Hamilton WL, Siegel M, Sullivan EM. Individual, Social-Normative, and Policy Predictors of Smoking Cessation: A Multilevel Longitudinal Analysis. Am J Public Health. 2010;100(3):547-554. doi:10.2105/AJPH.2008.150078

33. Yang JJ, Song M, Yoon H-S, et al. What Are the Major Determinants in the Success of Smoking Cessation: Results from the Health Examinees Study. PLoS One. 2015;10(12):e0143303. doi:10.1371/journal.pone.0143303

34. Edwards R. Hardening is dead, long live softening; time to focus on reducing disparities in smoking. Tob Control. 2019. doi:10.1136/tobaccocontrol-2019-055067

35. Feliu A, Fernandez E, Martinez C, Filippidis FT. Are smokers "hardening" or rather "softening"? An ecological and multilevel analysis across 28 European Union countries. Eur Respir J. 2019;54(3):1900596. doi:10.1183/13993003.00596-2019

36. Giovino G, Chaloupka F, Hartman A, et al. Cigarette smoking prevalence and policies in the 50 states: an era of change - the Robert Wood Johnson Foundation ImpacTeen Tobacco Chart Book. Buffalo, NY: University at Buffalo, State University of New York; 2009. https:// impacteen.uic.edu/generalarea_PDFs/chartbook_ final071009.pdf. Accessed November 18, 2020.

37. Thun M, Peto R, Boreham J, Lopez AD. Stages of the cigarette epidemic on entering its second century. Tob Control. 2012;21(2):96-101. doi:10.1136/tobaccocontrol-2011-050294

38. Piper M, Vasilenko S, Cook J, Lanza S. What a difference a day makes: differences in initial abstinence response during a smoking cessation attempt. Addiction. 2016;112(2):330-339. doi:10.1111/add.13613

39. Lukowski AV, Morris CD, Young SE, Tinkelman D. Quitline
Outcomes for Smokers in 6 States: Rates of Successful Quitting Vary by Mental Health Status. Nicotine Tob Res. 2015;17(8):924-930. doi:10.1093/ntr/ntu252

40. West R, Evins AE, Benowitz NL, et al. Factors associated with the efficacy of smoking cessation treatments and predictors of smoking abstinence in EAGLES. Addiction. 2018;113(8):1507-1516. doi:10.1111/add.14208

41. Graham H, Inskip HM, Francis B, Harman J. Pathways of disadvantage and smoking careers: evidence and policy implications. J Epidemiol Community Health. 2006;60(Suppl 2):7-12. doi:10.1136/jech.2005.045583

42. Lidon-Moyano C, Martin-Sanchez J, Saliba P, Graffelman J, Martinez-Sanchez J. Correlation between tobacco control policies, consumption of rolled tobacco and e-cigarettes, and intention to quit conventional tobacco, in Europe. Tob Control. 2017;26(2):149-152. doi:10.1136/tobaccocontrol-2015-052482

43. Martinez-Sanchez J, Fernandez E, Fu M, et al. Smoking Behavior, Involuntary Smoking, Attitudes towards Smoke-Free Legislations, and Tobacco Control Activities in the European Union. PLoS One. 2010;5(11):e13881. doi:10.1371/journal.pone.0013881

44. Feliu A, Filippidis FT, Joossens L, et al. Impact of tobacco control policies on smoking prevalence and quit ratios in 27 European Union countries from 2006 to 2014. Tob Control. 2018;28(1):101-109. doi:10.1136/tobaccocontrol-2017-054119

45. Filippidis F, Laverty A, Mons U, Jimenez-Ruiz C, Vardavas C. Changes in smoking cessation assistance in the European Union between 2012 and 2017: pharmacotherapy versus counselling versus e-cigarettes. Tob Control. 2019;28(1):95100. doi:10.1136/tobaccocontrol-2017-054117

46. Hartmann-Boyce J, McRobbie H, Bullen C, Begh R, Stead LF, Hajek P. Electronic cigarettes for smoking cessation. Cochrane Database Syst Rev. 2016;9(9):CD010216. doi:10.1002/14651858.CD010216.pub3

47. Bogdanovica I, Godfrey F, McNeill A, Britton J. Smoking prevalence in the European Union: a comparison of national and transnational prevalence survey methods and results. Tob Control. 2011;20(1):e4. doi:10.1136/tc.2010.036103

48. McDonald S, Perkins S, Walker M. Correlation between self-reported smoking status and serum cotinine during pregnancy. Addict Behav. 2005;30(4):853-857. doi:10.1016/j.addbeh.2004.08.016

49. Wong SL, Shields M, Leatherdale S, Malaison E, Hammond D. Assessment of validity of self-reported smoking status. Health Rep. 2012;23(1):47-53. PMID:22590805.

50. Morales N, Romano M, Cummings K, et al. Accuracy of self-reported tobacco use in newly diagnosed cancer patients. Cancer Causes Control. 2013;24(6):1223-1230. doi:10.1007/s10552-013-0202-4

51. Stelmach R, Fernandes F, Carvalho-Pinto R, et al. Comparison between objective measures of smoking and self-reported smoking status in patients with asthma or COPD: are our 
patients telling us the truth? J Bras Pneumol. 2015;41(2):124132. doi:10.1590/S1806-37132015000004526

ACKNOWLEDGEMENTS

The authors thank the staff at the Imperial College London School of Primary Care and Public Health for their technological support.

\section{CONFLICTS OF INTEREST}

The authors have completed and submitted the ICMJE Form for Disclosure of Potential Conflicts of Interest and none was reported.

\section{FUNDING}

This work was partially supported by a grant from the European Union (Horizon 2020 HCO-6-2015; EUREST-PLUS: 681109) awarded to CIV. The funders had no role in study design, data collection and analysis, decision to publish, or preparation of the manuscript.

\section{AUTHORS' CONTRIBUTIONS}

$\mathrm{CMC}$ and FTF analyzed and interpreted the dataset. CMC prepared the manuscript which was edited by FFF and CIV. All authors read and approved the final manuscript.

PROVENANCE AND PEER REVIEW

Not commissioned; externally peer reviewed. 